as 8 काillu

LA-4981-MS

4h. $2 \geq 41$

AN INFORMAL REPORT

\title{
斨ATTER
}

\section{Some Properties of}

\section{Several High-Density Composites}

THIS DOCUMENT CONFIRMED AS UNCLASSIFIED DIVISION OF CLASSIFICATION BY OHKahatamk

DATE $18 / 3 / 72$ 
This report was prepared as an account of work sponsored by the United States Government. Neither the United States nor tive United States Atomic Energy Commission, nor any of their employees, nor any of their contractors, subcontractors, or their employees, makes any warranty, express or im. plied, or assumes any legal liability or responsibility for the accuracy, completeness or usefulness of any information, apparatus, product of process disclosed, or represents that its use would not infringe privately owned rights.

In the interest of prompt distribution, this LAMS report was not edited by the Techrical Information staff.

Printed in the United States of America. Available from National Technical Information Service

U. S. Department of Commerce

5285 Port Royal Road

Springfield, Virginia 22151

Price: Printed Copy $\$ 3.00$; Microfiche $\$ 0.95$ 


\section{LA-4981-MS}

An Informal Report UC. 25

ISSUED: July 1972

\title{
Some Properties of \\ Several High-Density Composites
}

\author{
by
}

\author{
D. T. Eash \\ E. G. Zukas \\ W. V. Green
}

NOTICE

This report was prepared as an account of work sponsored by the United States Government. Neither the United States nor the United States Atomic Energy Commission, nor any of their employees, nor any of their centractors, subcontractors, or their employees,

makes any warranty, express or implied, or assumes any

legal liability or responsibility for the accuracy, com-

pleteness or usefulness of any information, apparatus,

product or process disclosed, or represents that its use

would not infringe privately owned rights. 
SOME PRO PERTIES OF SEVERAL HIGH-DENSITY COMPOSITES

by

D. T. Eash, E. G. Zukas and W. V. Green

\begin{abstract}
Three commercial high-density composites were studied. These composites were made by powder metallurgy techniques where high-density was achieved by liquid-phase sintering tungsten powder with nickel and iron, and perhaps minor amounts of other additives. Tensile tests, compressive tests and bend-ductility tests were run at various temperatures, but generally over the range from $-80^{\circ} \mathrm{C}$ to $200^{\circ} \mathrm{C}$. Fractography was done using the scanning electron microscope. Young's modulus, shear modulus and Poisson's Ratio were determined by sonic methods from liquid nitrogen temperature up to $500^{\circ} \mathrm{C}$.

Fractography studies showed that low temperature failure was by cleavage of the body-centered-cubic tungsten-rich dispersoids, and at the higher temperatures, by ductile tearing of the face-centered-cubic matrix. The transition from one mode of failure to the other occurred in the vicinity of room temperature. Thus, the course for future study can be divided very nicely into two parts. Below room temperature, the tendency toward cleavage of the dispersoids must be lessened to achieve adequate ductility, whereas above room temperature, the matrix must be strengthened. Since alloying additions will be partitioned between the dispersoids and the matrix, the proper alloying addition will have to ductilize, and perhaps soften, the tungsten-rich dispersoids while at the same time hardening and strengthening the matrix.
\end{abstract}

\section{INTRODUCTION}

During a recent survey on high density, high strength alloys having some room temperature ductility, ${ }^{1}$ the class of materials, composites, appeared to have properties approaching those required. Composite materials may be defined as those having two or more separable components (phases) which have been combined into an aggregate to meet some specific engineering requirement. Composite materials are usually unique in that the properties of the composite are not attainable in any single component.

In spite of the new and current prominence of work on new composites, composites as such are hardly new materials. Coated metals, fiberglass, reenforced plastics, bimetallic switches, and even bamboo and paper are composites. New technology, better understanding of single phase materials and new demanding needs place composites in an important position in today's materials science.

\section{LITERATURE SUMMARY}

The specific eingineering need that motivated the work discussed in this report was for a material with a very high density, high tensile and yield strengths, a high elastic modulus, a high compressive strength and good ductility. The material cost should be reasonable, there should be continued availability, and the feasibility for producing large pieces, perhaps to 100 pounds or 
more, should be possible. Either uranium alloys or tungsten base composites were prime candidates.

Fortunately, it didn't appear necessary to develop a new process combining various materials into aggregates with the desired combination of properties, since an existing class of composite materials ${ }^{2}$ appeared to have the required properties. The first tungsten composite (called the "heavy alloy") was described in 1938 by Smithells and his associates. ${ }^{3,4}$ They were searching for a high-density, small size radiation shield for use in radium therapy; something having a substantially greater density than lead or lead-base alloys. Tungsten was the only high density material readily available at reasonable cost. However, it was impossible to find a sintering furnace which was capable of sintering large compacts (100 pounds or so) of the desired shape at $3000^{\circ} \mathrm{C}$, and melting furnaces having this capability still haven't been developed. As a possible solution to the problem, perhaps the tungsten particles could be glued together with copper by sintering a pressed powder compact above the melting point of copper. The low density of the sintered pieces indicated excessive hydrogen absorption by the copper; a pinch of nickel which is completely soluble in the copper should reduce hydrogen pickup and perhaps increase the density. The unexpected high density obtained on these $\mathrm{W}-(\mathrm{Ni}+\mathrm{Cu})$ compacts sintered for very short time $s$ was indicative of unusual behavior. Over 100 compositions were studied in an attempt to determine the :easons for this behavior and to find the compositions which had the highest densities. On the basis of the results of their experimental program, they concluded that:

1. Copper, which is mutually insoluble with tungsten, when used as the matrix did not yield composites of high density.

2. Nickel dissolved too much tungsten (52\%) and became too brittle.

3. The ratio of 2 parts nickel to 1 part copper gave the best product.

4. This 2Ni:1Cu matrix dissolved 16\% tungsten.

5. For 1-2 micron tungsten powder, full density was achieved in about ten minutes.
6. The use of a larger size tungsten powder required longer sintering times to achieve full density, about 8 hours being required for 50-60 micron tungsten powder.

7. The tungsten dispersoids were much larger than the original powder size, leading to the conclusion that the tungsten was dissolved by the matrix and subsequently reprecipitated.

8. The tungsten dispersoids were single crystals.

9. The matrix was face-centered-cubic.

10. That radiation shields of 100 pounds having a high density could be readily made.

The finished composites, then, are tungsten singie cyrstal-dispersoids embedded in a face-centered-cubic matrix $(16 \% \mathrm{~W}-56 \% \mathrm{Ni}-28 \% \mathrm{Cu})$. Their properties slould be interesting since the brittle tungsten-tungsten grain boundaries are absent, and face-centered cubic materials (the matrix) do not exhibit the ductile-brittle transition which limits the low-temperature ductillty of body-centered-cubic materials.

Surprisingly, very little further study was done on these composites until about 1960. In this revived effort, the copper was replaced by iron, and other additions made to change the matrix properties. A number of studies were conducted to determine the elastic behavior and mechanical properties of these composites. ${ }^{5-15}$ Commercial alloys are now avallable with densities up to $18.5 \mathrm{~g} / \mathrm{cm}^{3}$, and with yield strengths of about 100,000 psi. Recently, a patent ${ }^{16}$ was issued for a composite containing $90 \% \mathrm{~W}-6 \% \mathrm{Ni}-2 \% \mathrm{Mo}-1.5 \% \mathrm{Fe}-0.5 \% \mathrm{Ru}$. This composite supposedly has a tensile strength of 160,000 psi, a proportional limit of $133,000 \mathrm{psi}, 10 \%$ elongation and a density of $17.25 \mathrm{~g} / \mathrm{cm}^{3}$.

This study was initiated to a) extend the mechanical property data of a few of the commercially available composites from $-196^{\circ} \mathrm{C}$ to over $200^{\circ} \mathrm{C}$, and b) to study their fracture behavior over this same temperature range. If these commercial composites did not have the strength and ductility required for the intended use, then perhaps the results of this study would suggest reasonable avenues of research and development for improvement. 

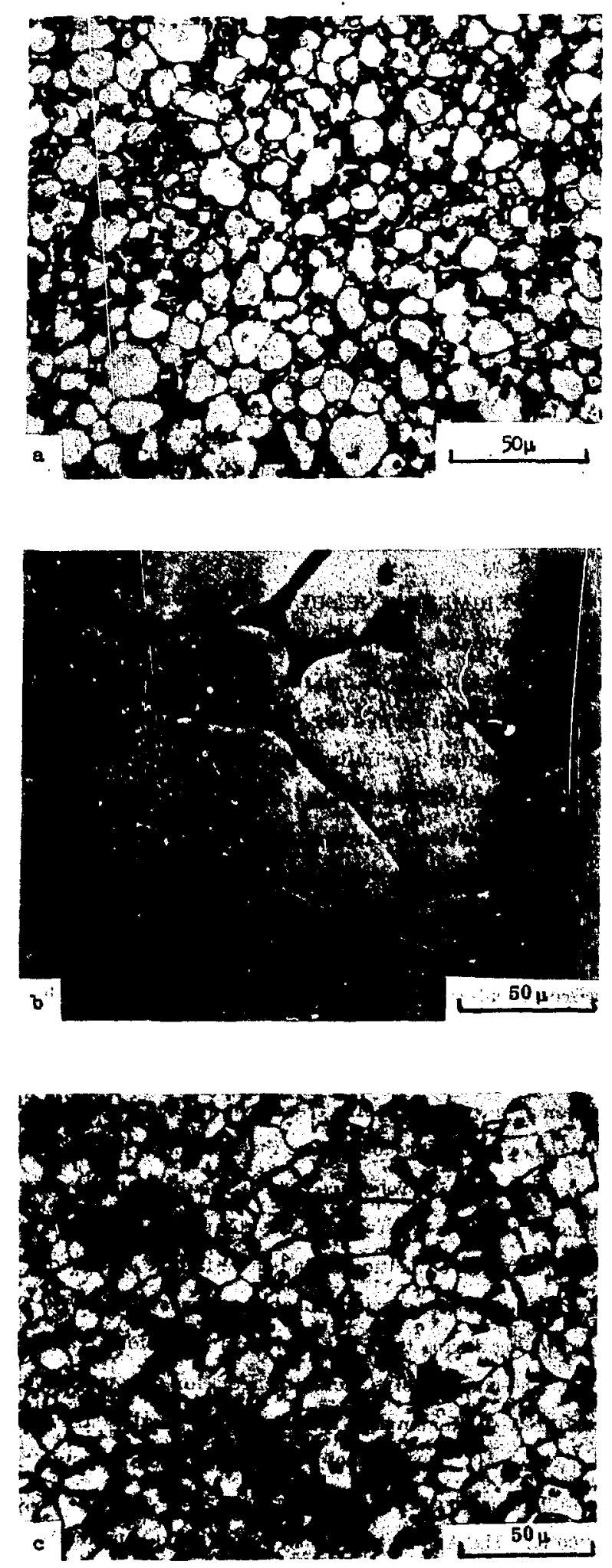

Fig. 1. Photomicrographs of (a) Gyromet 1100 , (b) Kennertium W-2, and (c) Kulite A-5.

\section{EXPERIMENTAL TECHNIQUES}

In this program, we studied three different commercial composites. They were: (1) Gyromet $1100^{*}(90 \% \mathrm{~W}-$ $4 \% \mathrm{Ni}-2 \% \mathrm{Fe}-4 \% \mathrm{Mo} ; \mathrm{p}=17.19 \mathrm{~g} / \mathrm{cm}^{3}$ ), (2) Kennertium $\mathrm{W}-2^{* *}\left(96 \% \mathrm{~W}-4 \%(\mathrm{Ni}+\mathrm{Fe}) ; p=18.49 \mathrm{~g} / \mathrm{cm}^{3}\right.$, and (3) Kulite A-5 ${ }^{* * *}\left(95 \% \mathrm{~W}-5 \%(\mathrm{Ni}+\mathrm{Fe}) ; p=17.6 \mathrm{~g} / \mathrm{cm}^{3}\right)$.

Photomicrographs of these three composites are shown in Figure 1. The tungsten dispersoids appear spherical in shape for both the $G 1100$ and the $W-2$, the big difference being the much larger dispersoid size in $W-2$. The volume of the average dispersold in the W-2 is several bundred times that in the $G 1100$. The A-5 dispersoids are about the same size as those in $G 1100$, but they are almost angular in shape, suggesting perhaps that the sintering temperature was not kept high enough to maintain liquid phase sintering during the final stages, the result of tungsten being dissolved in the matrix during liquid phase sintering thereby increasing the melting temperature of the matrix.

Brittle-ductile transition temperature bend tests as used by others, ${ }^{17}$ tensile and compression tests at various temperatures, and scanning electron microscopy on fractured surfaces were used to study these materials either in the as-received, cold or warm rolled, and grain coarsened state (achieved by additional sintering of the as-received material).

Additional studies suggested by us were initiated elsewhere. Auger spectroscopy on fracture surfaces will be used to determine if the low ductility is due to chemical segregation of impurities to an interface. D. Stein, now at Michigan Tech, has pioneered this technique ${ }^{18}$ and will examine specimens for LASL. T. Mitchell, at Case Western Reserve, has one of the few high energy transmission electron microscopes available (650, 000 volts), as well as a cathodic vacuum thinner capable of thinning multiphase materials. Mitchell will also assiat us. The advantages of his microscope are:

1. The high energy electron beam can penetrate about 1 micron of a heavy metal composite, about ten times that possible locally. The thicker sections not only should better represent the bulk material, but also

\footnotetext{
* P. R. Mallory Company.

** Kennametal, Inc.

*** Kulite Tungsten Corporation.
} 


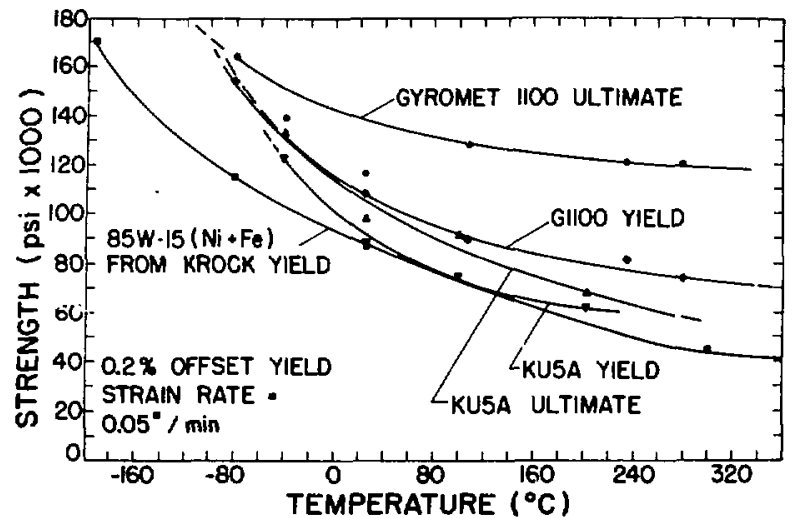

Fig. 2. Tensile properties of Gyromet 1100, Kulite A-5 and an $85 \% \mathrm{~W}-15 \%(\mathrm{Ni}+\mathrm{Fe})$ alloy from Reference 6.

such thicker specimens should be less likely to crumble during handling.

2. More favorable spherical aberration conditions with the higher voltage allow selected area diffraction on much smaller areas. The crystal structure of the matrix or binder phase can be cesolved more easily.

3. The practical resolution of the high voltage microscope will be better since the resolution varies as $1 / \lambda^{2}$ where $\lambda$ is the wave length of the electrons. The results of Stein and Mitchell will be reported later by them.

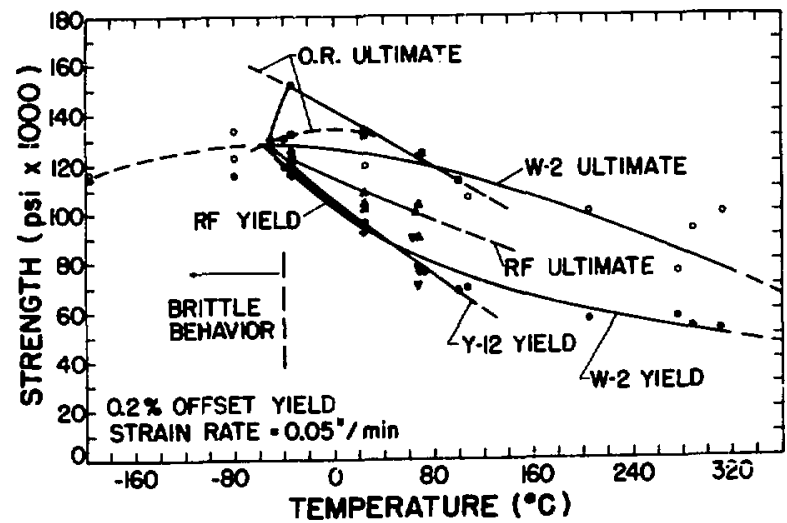

Fig. 3. Tensile properties of Kennertium W-2, small size specimens of W-2 from Rocky Flats, and a similar composite produced by $\mathrm{Y}-12$, Oak Ridge.

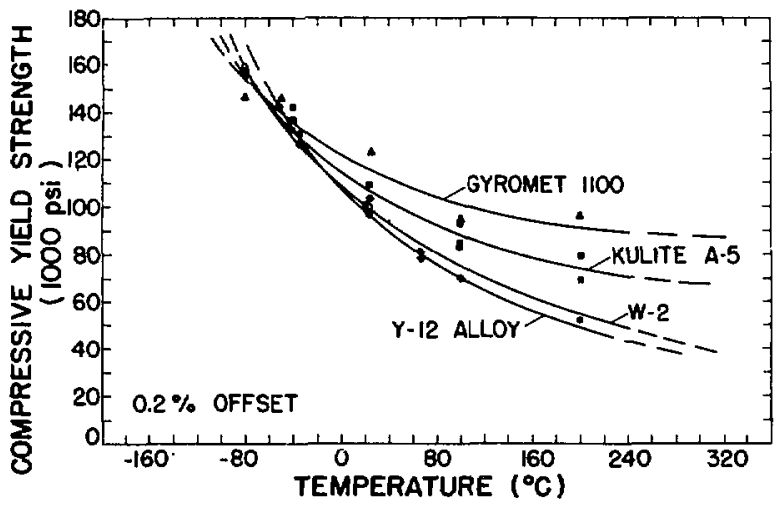

Fig. 4. Compressive yield strengths at $0.2 \%$ offeet for several heavy metal composites.

\section{EXPERIMENTAL RESULTS}

The ultimate tensile strengths and yield strengths for $G 1100$, Kulite $A-5$, and the yield strengths for an $85 \% \mathrm{~W}-15 \%(\mathrm{NI}+\mathrm{Fe})$ alloy reported by Krock ${ }^{6}$ are shown in Figure 2. Similar results for $W-2$, a smaller size specimen of W-2 purchased by Rocky Flats (R. F.), and a composite similar to $\mathrm{W}-2$ manufactured by $\mathrm{Y}-12$, Oak Ridge, are shown in Figure 3. The G 1100 had the highest tensile and yield strengths at temperatures above $0^{\circ} \mathrm{C}$. For all of the other composites, the yield strengths were essentially the same from $-40^{\circ} \mathrm{C}(125,000 \mathrm{psi})$ to $+100^{\circ} \mathrm{C}(70,000 \mathrm{psi})$. Brittle behavior is prevalent in all of these composites below $-40^{\circ} \mathrm{C}$. The $\mathrm{Y}-12$ alloy was given a vacuum degassing treatment at $1200^{\circ} \mathrm{C}$ after sintering, presumably to remove the remaining hydrogen. Even though this procedure did not result in any notable change in the yield strength, the composite survived considerably more plastic strain before failure, and had a higher ultimate strength probably as a result of workhardening during the additional straining before fracture.

The compressive yield strongths for Gy romet 1100 , Kulite A-5, Kennertium $\mathrm{W}-2$ and the $\mathrm{Y}-12$ alloy are shown in Figure 4. The $G 1100$ has the highest compressive yield strength over the temperature range of $-40^{\circ} \mathrm{C}$ to $200^{\circ} \mathrm{C}$. The A-5 has a slightly lower yield, and the $\forall-2$ and Y-12 alloys are the weakest. At temperatures below 
$-40^{\circ} \mathrm{C}$, the compressive yield strengths are about the same for all of these composites.

The bend-ductility angle versus testing temperature for these composites are shown in Figure 5. To make the results more meaningful to the reader, the values for glass, W-25\% Re rolled $25 \%$, recrystallized $0.015 "$ and $0.030^{\prime \prime}$ tungsten sheet, and steel strip are includce. on the plot. Since glass is brittle, the bend angle shows the contribution of elastic deflection alone. Steels undergo a sharp ductile-brittle transition, and such behavior was readily demonstrated by this test. Recrystallized tungsten sheet is a common material known for its glass-like brittleness. The $\mathrm{W}-25 \%$ Re points out the improved ductility of this alloy over pure tungsten, but contrary to the extensive publicity proclaiming low temperature ductility the alloy is still quite brittle. The $\mathrm{W}-2$ alloy is more ductile than $G 1100$ at room temperature and above; they are about the same at lower temperatures. The W-2 deforms adequately to pass through the bend-ductility die at temperatures of $100^{\circ} \mathrm{C}$ and above, whereas the $\mathrm{G} 1100$ still fractures during the bend-ductility test at $200^{\circ} \mathrm{C}$. If one assumed that a material which fractured at a bendductility angle of $90^{\circ}$ or more would perform satisfactorily, then the $\mathrm{W}-2$ would be satisfactory at temperatures above $45^{\circ} \mathrm{C}$ and the $\mathrm{G} 1100$ above $130^{\circ} \mathrm{C}$. For some uses, even less ductility might be tolerated. If we assumed that fracture at a bend-ductility angle of $30^{\circ}$ was

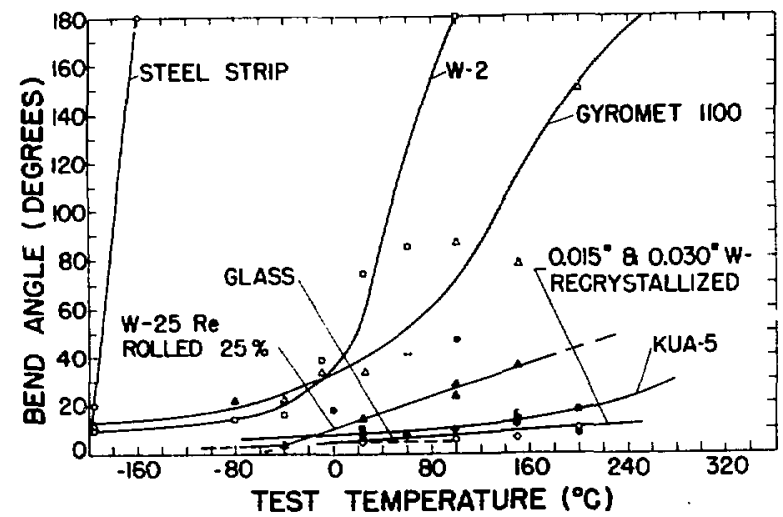

Fi. . 5. Bend-ductility test results for several commercial composites, and for a number of other materials. satisfactory, since considerable plastic deformation is required to even accomplish this, then bots yomposites could be used above $-15^{\circ} \mathrm{C}$. The A-s w'as brittle for all testing temperatures.

All of the above tests were run using a ram speed of $11 /$ minute. This corresponds to an average outerfiber strain rate of $4 \times 10^{-3} \mathrm{sec}^{-1}$. Genexally, testing at higher strain rates raises tha temperature of the ductile-brittle transition. If the loading rates under actual conditions of use are expected to be higher, then those materials which are satisfactory at the slower testing rates should be retested using loading rates similar to those expected under actual use conditions.

The elastic moduli $(E)$ for all of these composites from $-196^{\circ}$ to $500^{\circ} \mathrm{C}$ are plotted in Figure 6 . The room temperature moduli for the different composites varies pretty much as the ratio of tungsten to the matrix, consistent with predictions. 19,20 The elastic modulus decreases as the temperature is increased, consistent with the behavior of pure tungsten ${ }^{21}$ and the predictions of the laws for mechanical mixtures. The shear modulus (G), also shown in Figure 6, decreases slowly as the temperature is increased. Poisson's ratio (E/2G - 1) is also shown.

Scanning =lectron microscopy was used to study the fracture appearance of specimens testid at the various temperatures. For bend test specimens, only those that

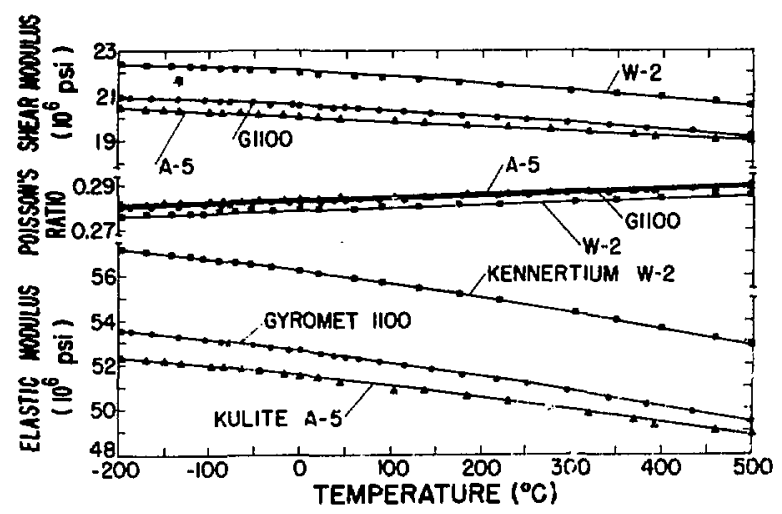

Fig. 6. Elastic modulus, shear modulus and Poisson's Ratio versus temperature fou three commercial composites. 

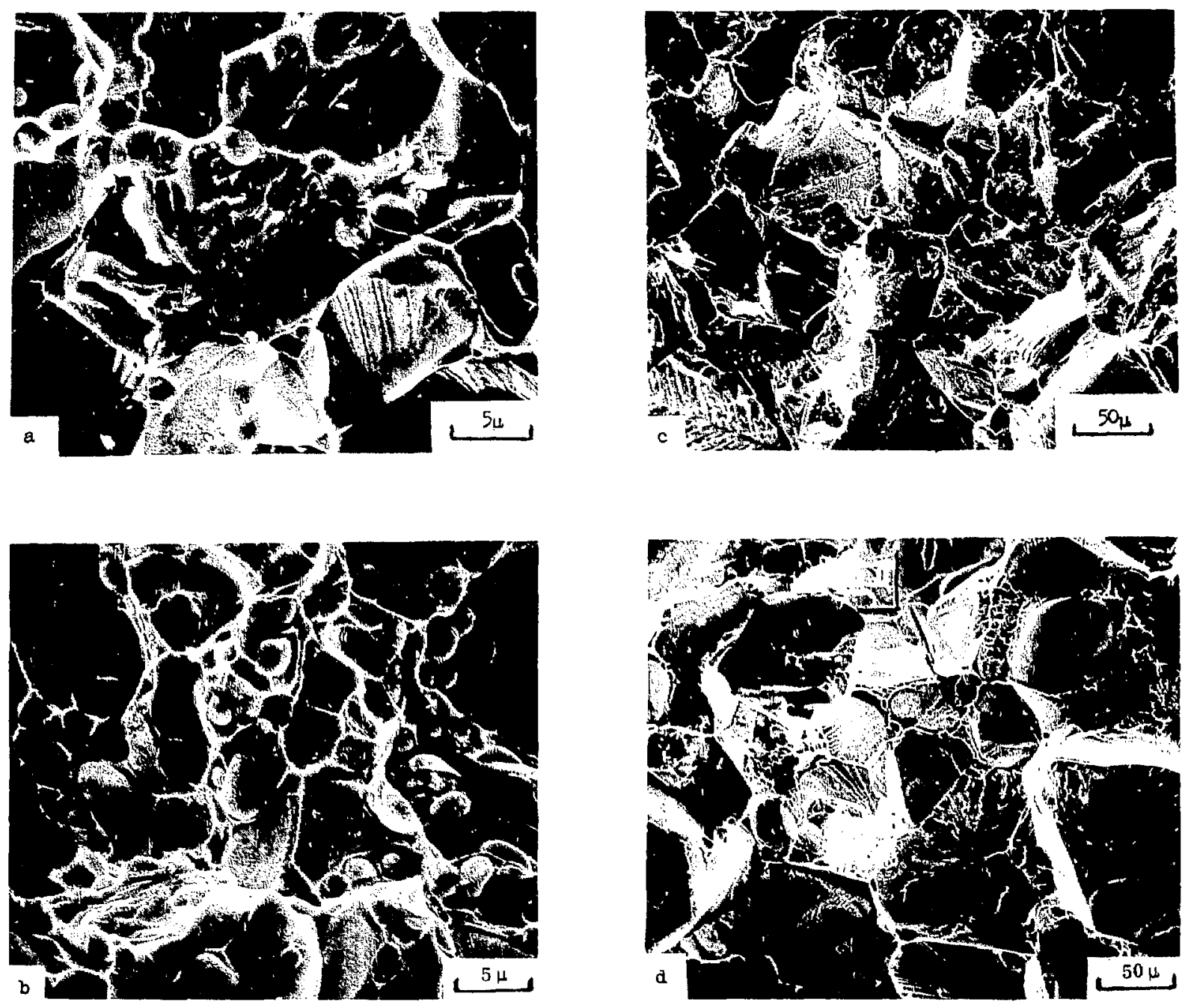

Fig. 7. Scanning electron micrographs of fracture surfaces of bend test specimens of (a) G $1100 @-40^{\circ} \mathrm{C}$, (b) $\mathrm{G} 1100$ (a) $200^{\circ} \mathrm{C}$, (c) $\mathrm{W}-2 @-80^{\circ} \mathrm{C}$ and (d) $\mathrm{W}-2 @ 60^{\circ} \mathrm{C}$.

fracture can be examined, thereby eliminating fracture studies on those having good ductility. Fracture surfaces of tensile specimens were used to supplement the bend test results, and to insure that the fracture mechanisms were similar in both instances. Scarning election micrographs of the fracture surfaces of bend-test specimens of $\mathrm{W}-2$ at $-80^{\circ} \mathrm{C}$ and $+60^{\circ} \mathrm{C}$, and for $\mathrm{G} 1100$ at $-80^{\circ} \mathrm{C}$ and $+200^{\circ} \mathrm{C}$ are shown in Figure 7. Fracture surfaces for tensile test specimens of $W-2$ at $-196^{\circ} \mathrm{C}$ and $+300^{\circ} \mathrm{C}$, and for $\mathrm{G} 1100$ at $-40^{\circ} \mathrm{C}$ and $+300^{\circ} \mathrm{C}$ are shown in Figure 9. A study of these micrographs leads to a very important conclusion. Fracture at the lower temperatures is predominantly by tungsten dispersoid cleavage with the matrix still showing good ductility. Fracture at the higher temperatures is caused mainly by the matrix pulling away from the tungsten dispersoids although some dispersoid cleavage still occurs. Thus, for low temperature ductility, the tungsten dispersoids must be made more ductile with less tendency toward cleavage fracture, whereas for high temperature strength, the mechanical properties of the matrix must be improved, and hopefully at the same time, the matrix-dispersoid interface strengthened. 

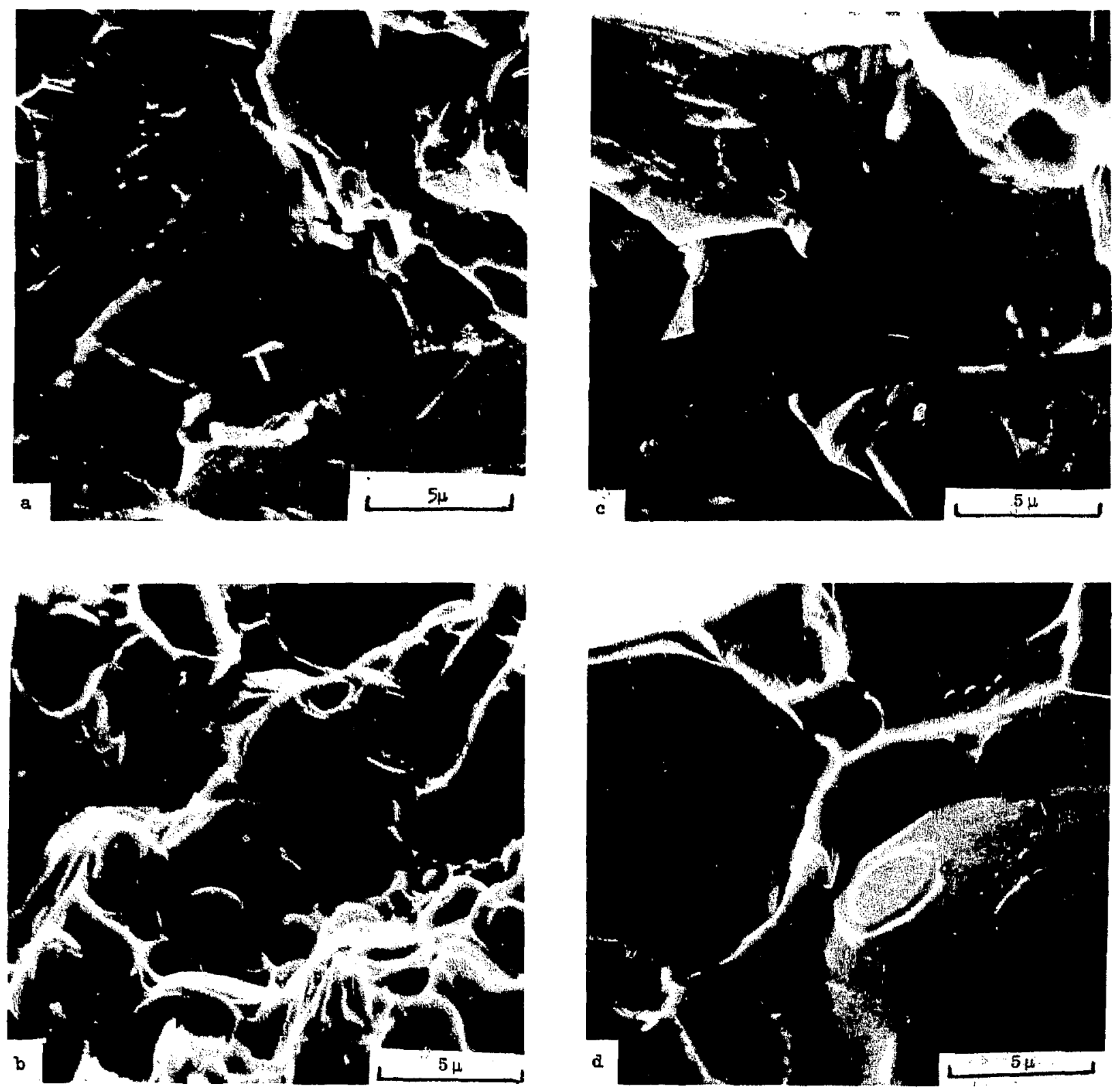

Fig. 8. Scanning electron micrographs of fracture surfaces of tensile specimens of (a) G $1100 @-40^{\circ} \mathrm{C}$, (b) G $1100 @$ $300^{\circ} \mathrm{C}$, (c) W-2@-196 ${ }^{\circ} \mathrm{C}$ and (d) W-2@300 $\mathrm{C}$.

One possible method for improving the ductility of the dispersoids is to increase their dislocation density so that deformation by slip would be favored over cleavage fracture. Perhaps rolling would accomplish this, and at the same time, strengthen the matrix. To test this hypothesis, a number of bend-ductility specimens were rolled out of a hydrogen atmosphere furnace to various reductions in cross-sectional area (up to 50\%) at temperatures to $1200^{\circ} \mathrm{C}$. At temperatures above $1000^{\circ} \mathrm{C}$, all of the specimens split during the rolling process. The remaining specimens were tested at room temperature where the tungsten particle cleavage and matrix failure take place simultaneously during bending in as-received specimens. The bend test results as a function of rolling 


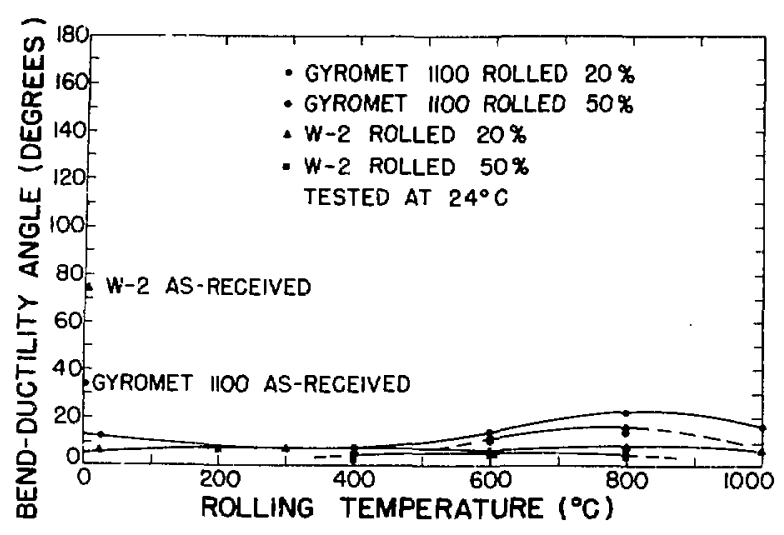

Fig. 9. Room temperature bend ductility versus rolling temperature for specimens rolled various amounts up to $50 \%$ reduction in cross-sectional area.

temperature for some of the specimens are shown in

Figure 9. In all cases, rolling had a very bad effect on ductility. For a rolling temperature of about $800^{\circ} \mathrm{C}$, there was a slight peak in the bend-ductility curve, indi-cating that this might be the temperature to use for some other type of mechanical deformation process intended to promote ductility.

Microstructural studies showed that cleavage of a few of the tungsten single crystal dispersoids occurred on rolling below $300^{\circ} \mathrm{C}$, and this could readily initiate fracture. However, there was no evidence for dispe soid cleavage caused by rolling at $400^{\circ} \mathrm{C}$ and above. The poor bend ductility of specimens rolled at $400^{\circ} \mathrm{C}$ and above might be due to any one of a number of reasons. One should not assume similar behavior for slow pressing or for other mechanical treatments especially where the forces are more nearly hydrostatic. The possibility for ductility improvement by increasing the mobile dislocation density to promote deformation by slip should be studied further.

\section{DISCUSSION}

The scanning electron microscope studies showed that the modes of failure in the liquid-phase sintered composites were predominantly tungsten-rich dispersoid cleavage at low temperatures, matrix failure at the high temperatures, and a cornbination of the two modes at the

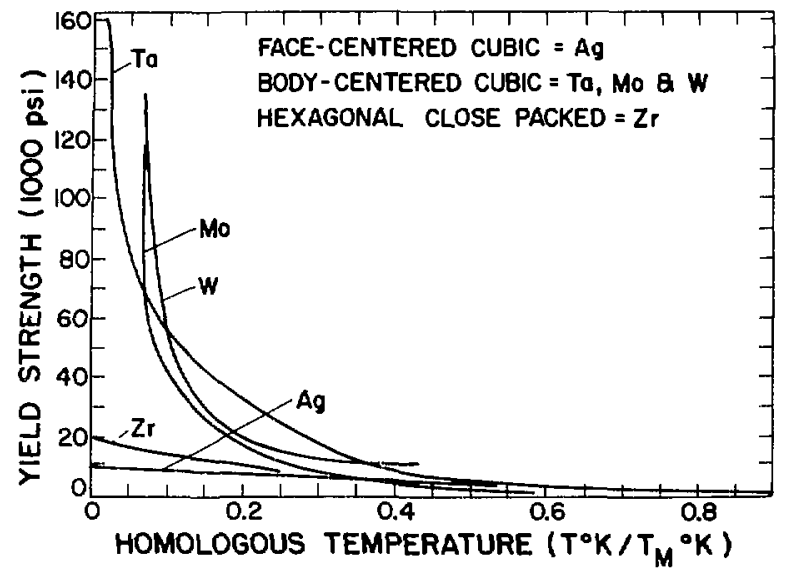

Fig. 10. The effect of temperature on the yield strength behavior for metals having different crystal structures. (From References 22, 23 and 24.)

intermediate temperatures. Thus, the temperature of the test is all-important. At room temperature where both failure modes operate, a change in composition, prior deformation, or some other variable might cause an increase or decrease in the bend ductility. This could be caused by shifting the temperature dependence of the bend duct ' 'ity either to higher or lower temperatures while still maintaining the same general curve shape. However, there is the possibility that only the shape of the bend-ductility versus temperature curve might change. Thus, an improvement in bend-ductility for room temperature tests alone do not necessarily mean better ductility at $0^{\circ} \mathrm{C}$ or at $60^{\circ} \mathrm{C}$ since the mode of fracture is a combination of both dispersoid particle cleavage and matrix failure occurring simultaneously.

The reason for the transition of fracture behavior from cleavage through the tungsten-alloy dispersoids at low temperatures to ductile tearing of the binder matrix at high temperatures might be related to the change in yield behavior with temperature. The yield strengths of tantalum, ${ }^{22}$ molybdenum, tungsten, silver and zirconium $^{23}$ as a function of temperature are shown in Figure 10. Note that the yield strength of the facecentered-cubic metals, as illustrated for silver, increases only slightly with decreasing temperature below $0.2 \mathrm{~T}_{\mathrm{m}}$ (where $\mathrm{T}_{\mathrm{m}}$ is the melting temperature of the metal in degrees Kelvin). For the body-centered-cubic 


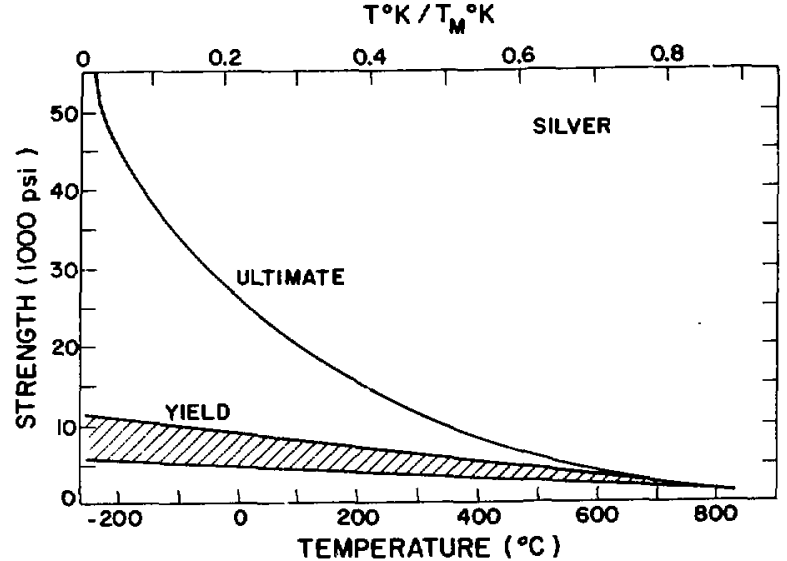

Fig. 11. The effect of temperature on the yield strength and ultimate strength of silver. (From Reference 24.)

metals, the yield strengths increase rapidly with decreasing temperature, there is little difference between their yield strengths and ultimate strengths, and for a large number of bcc metals, brittle fracture occurs. The yield strengths for fcc metals increases only slightly with decreasing temperature while their ultimate strengths increase rapidly, as shown in Figure 11 for silver. ${ }^{24}$ Thus, the difference between the yield strength and ultimate strength increases rapidly, there is a marked increase in strain hardening with decreasing temperature, and the metal remains ductile. At ambient temperature, the bec tungsten-alloy dispersoids are at $0.08 \mathrm{~T}_{\mathrm{m}}$ and the fcc matrix at $0.17 \mathrm{~T}_{\mathrm{m}}$. Therefore, at room temperature and below, the composite consists of brittle tungsten-rich dispersoids embedded in a matrix that is reasonably ductile and has a high capacity for work-hardening; so brittle failure takes place by cleavage through the dispersoids. At the higher temperatures, the tungsten-rich dispersoids achieve some degree of ductility, the work-hardening capacity of the fcc matrix is very much reduced, and failure is through the matrix. These statements are consistent with the observed transition in failure mode, which unfortunately occurs in the temperature range of anticipated use. Therefore, test results at a single test temperature will not represent the material behavior over the actual temperature range of interest.
Since the low temperature behavior is governed by tungsten particle cleavage, improvement will depend to some extent on understanding this behavior. Extensive study on the behavior of tungsten single crystals has already been done. ${ }^{25-30}$ Tests on tungsten single crystals show that the tensile strength and yield strength values are very strongly orientation dependent. For example, the $0.2 \%$ offset yield for the [100] orientation at room temperature is approximately $50,000 \mathrm{psi}$, and about 110-120,000 psi for the [110] and [111] orientations. Lowering the test temperature to $-196^{\circ} \mathrm{C}$ increases the yield strength in the $[100]$ orientation to about 130,000 psi and to over 200,000 psi for the [110] and [111] orientations. The $[100]$ crystals show the lowest strain to fracture, but even these crystals can be strained to more than $5 \%$ at $-196^{\circ} \mathrm{C}$. The $[100]$ crystals workharden at a much higher rate than do crystals of the other orientations. These results at first glance would indicate that $\mathrm{W}-\mathrm{Ni}-\mathrm{Fe}$ or $\mathrm{W}-\mathrm{Ni}-\mathrm{Cu}$ composites should be adequately strong and have good ductility even to very low temperatures. They do not, so we must understand why if we are to improve the composites without depending entirely on luck.

The observations of Beardmore and $\mathrm{Hull}^{29} \mathrm{might}$ be pertinent as follows. They found that grip constraints and superficial defects resulted in brittle fracture in crystals close to the [100] orientation, which they attributed to the rapid work-hardening during straining for this crystallographic orientation. The cleavage planes were usually [100]. In the polycrystalline composite, many crystals or dispersoids (since they are single crystals) would have their [100] direction lined up in the tensile loading direction. Neighboring crystals and the binder phase would act as grip constraints causing brittle behavior of those unfavorably oriented crystals. Small deformation would cause cracks to traverse these. Brittle failure would result when the Griffith criterion is satisfied. Also, in the sintered composites, the "notches" at the particle-particle junction in cases where tungsten particles are in direct contact would appear to be perfect sites for the initiation of cleavage cracks. There are a number of sites in these composites 

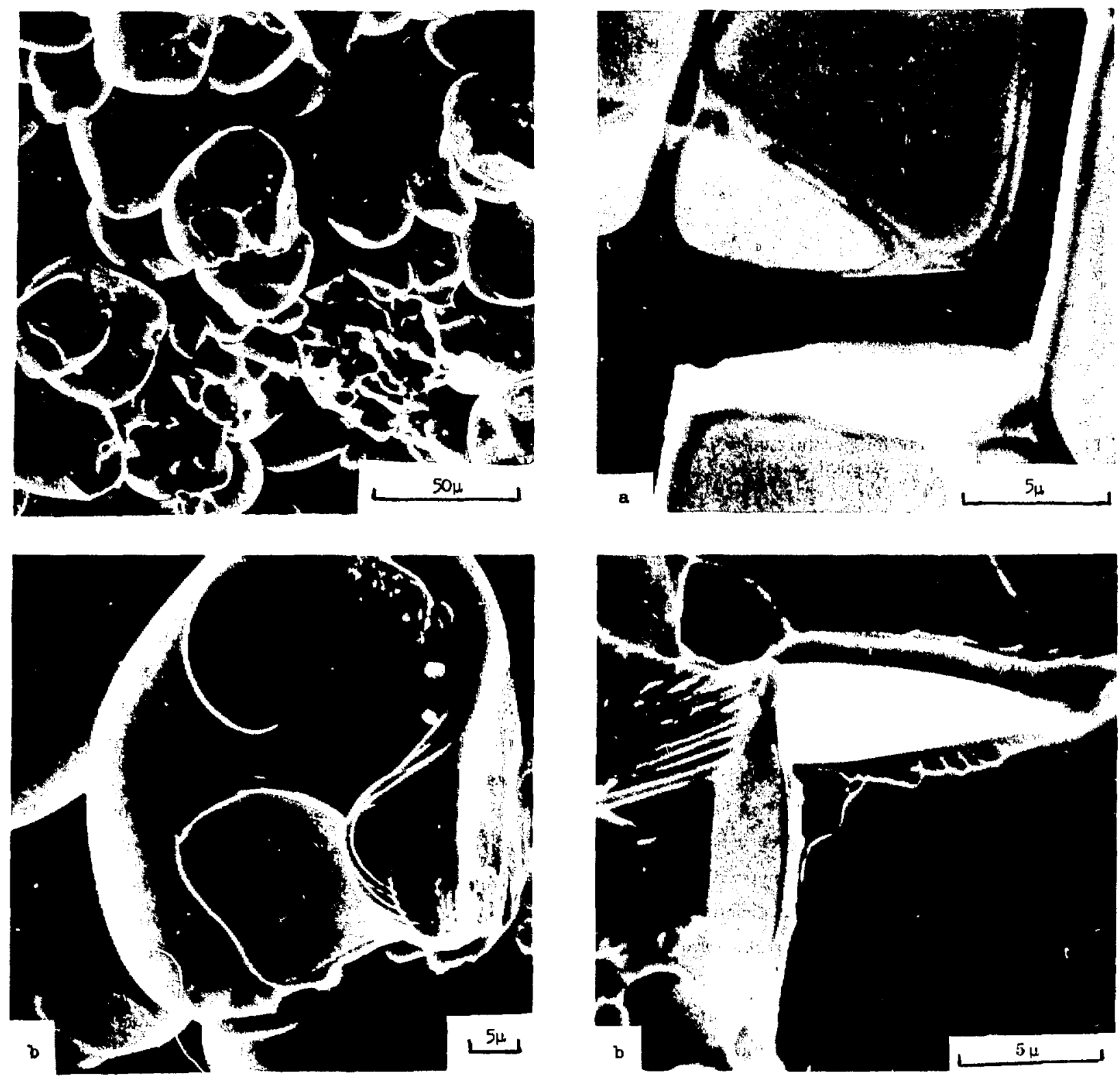

Fig. 12. Site in W-2 composite devoid of matrix phase. (a) Low magnification, and (b) high magnification.

where the matrix phase is missing, either for one reason or another such as insufficient mixing of the powders, or the volume decrease in the matrix on sintering. One such site is shown in Figure 12. This immediately raises the question, does the matrix improve low temperature ductility or not? To answer this question, a specimen of

Fig. 13. Fractured surface of G 1100 after distilling away a large part of the matrix phase.

(a) Matrix depleted zone, and (b) river pattern fracture. Note increased dispersoid size and cleavage fracture.

G 1100 was held in vacuum at a high enough temperature to distill off a large part of the matrix. The strueture of a fractured surface after this treatment is shown in Figure 13. The dispersoids increased in size during this vacuum treatment. Frateture was mainly by dispersoid cleavage. The yield strength wis athout half that of 
TABLE I

MECHANICAL PROPERTY RESULTS OF DRAWN AND ANNEALED TUNGSTEN WIRE FROM REFERENCE 35

\begin{tabular}{|c|c|c|c|c|c|}
\hline \multirow[b]{2}{*}{ Composition } & \multirow[b]{2}{*}{ Property } & \multirow{2}{*}{$\begin{array}{c}\text { As } \\
\text { Drawn }\end{array}$} & \multicolumn{3}{|c|}{ Annealing Temperatures } \\
\hline & & & $2750^{\circ} \mathrm{C}$ & $2850^{\circ} \mathrm{C}$ & $3000^{\circ} \mathrm{C}$ \\
\hline \multirow[t]{2}{*}{$w$} & Yield Strength, 1000 psi & 326 & 180 & 163 & -- \\
\hline & Elongation, & 0.2 & 0 & $\mathbf{0}$ & --- \\
\hline \multirow[t]{2}{*}{$\mathrm{W}-1 \% \mathrm{Re}$} & Yield Strength, $1000 \mathrm{psi}$ & 312 & 167 & 122 & (1) \\
\hline & Elongation, \% & 1.9 & 19.3 & 1.8 & 0 \\
\hline \multirow[t]{2}{*}{$W-3(y)$ Re } & Yield Strength, $1000 \mathrm{psi}$ & 390 & 187 & 155 & 140 \\
\hline & Elongation, \% & 1.8 & 25.7 & 27.6 & 9.0 \\
\hline \multirow[t]{2}{*}{$W-5 c h e$} & Yield Strength, 1000 psi & 390 & 188 & 147 & 137 \\
\hline & Elongation, \% & 1.6 & 16.0 & 23.9 & 11.5 \\
\hline \multirow[t]{2}{*}{$w-7 \%$ Re } & Yield Strength, $1000 \mathrm{psi}$ & 385 & 154 & 130 & 123 \\
\hline & Elongation, \% & 2.0 & 13.0 & 9.0 & 13.6 \\
\hline \multirow[t]{2}{*}{$\mathrm{W}-10 \%$ Re } & Yield Strength, $1000 \mathrm{psi}$ & 360 & 146 & 138 & -- \\
\hline & Elongation, \% & 1.6 & 18.2 & 7.5 & $--\infty$ \\
\hline \multirow[t]{2}{*}{$W-20 \%$ Re } & Yield Strength, 1000 psi & 377 & 162 & 163 & -- \\
\hline & Elongation, \% & 2.2 & 2.3 & 1.0 & $-\infty$ \\
\hline
\end{tabular}

(1) Brittle failure.

the original material, and fracture occuired after essentially zero elongation. Thus, it appears that the matrix exerts a very strong influence even at teniperatures where dispersoid cleavage fracture is predominant.

At low temperatures, the matrix phase and the dispersoids are both sufficiently strong, but cleavage fracture occurs, thereby lowering the ductility below that desired for structural applications. The problem, then, is to find some way in which cleavage type fracture of the tungsten-rich single crystal dispersoids can be inhibited, perhaps by particle size control, by alloying, or by mechanical treatments. Prior straining in compression to increase the mobile dislocation density in the tungsten jarticles might ! : . note slip along additional slip systems and lessen the tendency toward brittle fracture. Perhaps shock loading procedures could be used, especially for large pieces which would be difficult to deform by other techniques. Another solution inight be to orient the single crystal dispersoids preferentially so that there would be no [ 100$]$ planes in the direction of anticipated tensile stress. Directional sceding and sintering with a moving hot zone procucing a high temperature gradient would be a possible way to orient all dispersoids in a composite. Unfortunately, bcc metals have [100] growth occasionally. Or perhaps sintering in a magnetic field might have some influence. Another technique for improving low temperature ductillty might be by alloying to give ductile tungsten-alloy single crystal dispersoid particles. Also, a smaller dispersoid particle size, brought about by alloying or changing the sintering conditions, would increase the number of "notches" or stress concentration points and reduce the stress per "notch".

In trying to improve the low temperature ductility of tungsten, a number of investigators ${ }^{31-36}$ studied the softening effect of rhemium additions to tungsten. According to Garfinkle, ${ }^{31}$ although rhenium additions increase the proportiona] limit of $[100]$ oriented single crystals, the flow stress is decreased, and at the same time, the work-hardening is drastically reduced. These results suggest that a 3 to $5 \%$ addition of rhenium would be best for our use. Lamp wires of $0.008^{\prime \prime}$ diameter containing from 0 to $20 \%$ rhenium were annealed at 
temperatures to $3000^{\circ} \mathrm{C}^{35}$ and then tested at room temperature. Although the information seems inadequate, it suggests that a few per cent addition of rhenium would increase the low temperature ductility of the composites.

A partial listing of their results is given in Table I.

If softening of the tungsten is the answer to low temperature ductility in tungsten single crystals, then perhaps additions of alloying elements which are both cheaper and more abundant could be used in place of rhenium. Various alloying elements have been added to tungsten, 34,36 and indeed a number of them do have a softening effect. Small ruthenium 1 additions have a softening effect, and evidently improves the ductility of the tungsten dispersoids in composites. ${ }^{16}$ Other alloying additions which soften tungsten, and the amounts which give the softest alloy are: $\operatorname{Ru}-2 \%$, Re $-5 \%$, Os $-1 \%$, Ir -0.3 to $0.5 \%$, and $\mathrm{Pt}-2 \%$. Alloying additions which do not soften tungsten are $\mathrm{Mn}, \mathrm{Fe}, \mathrm{Co}, \mathrm{Ni}, \mathrm{Rh}$, and $\mathrm{Pd}$. A number of additional possible alloying elements which have not been studied, but are known to soften chromium, are $\mathrm{Ta}, \mathrm{Nb}$, $\mathrm{Hf}, \mathrm{Ti}$, and $\mathrm{Zr}$. Since chromium is similar in its mechanical property behavior to tungsten, small additions of those elements might soften tungsten.

At the higher temperatures of anticipated use, the ductility is adequate, whereas the yield strength is lower than desired. From the scanning electron microscopy results, the high temperature failure is predominantly ductile failure of the matrix. $\mathrm{Krock}^{8}$ studied alloys of the matrix composition $(24 \% \mathrm{~W}-53 \% \mathrm{Ni}-23 \% \mathrm{Fe})$ and fourd that the yield strength was less than $40,000 \mathrm{psi}$ at $27^{\circ} \mathrm{C}$. Therefore, some addition might be made which will strengthen the matrix. At the same time, its solubility in tungsten should be very limited (unless it is the same type addition used to ductilize the tungsten disperoid particles), otherwise it will end up predominantly in the tungsten, perhaps changing the properties of the single crystal dispersoids in a deleterious manner. Manganese and cobalt appear to be interesting possibilities. Perhaps very small additions of boron would be helpful. Unfortunately, there are no commercial alloys having a face-centered-cubic structure which are anywhere near the matrix composition, and there exists little previous research on similar compositions. Most known heattreatable alloys contain considerable carbon and are bodycentered-cubic under certain situations. Their use as matrix alloys appears undesirable since bcc metals usually show sharp ductile-brittle transitions, and since tungsten is a strong carbide former. Tungsten carbides are notoriously brittle. The controlling factor, however, might be the partition of the carbon between the tungsten and the matrix. There are no obvious additional methods to strengthen the matrix alloy without embrittlement to the tungsten-rich dispersoids. The improvement of the matrix alloy will require an experimental study.

\section{SUMMARY}

The tungsten composites are brittle at low temperatures and weak at the higher temperatures. Scanning electron microscopy has shown that the low temperature failure is by tungsten-rich single crystal dispersoid cleavage; the matrix is plastic but weak at the higher temperatures. Unfortunately, the transition temperature from dispersoid cleavage to matrix failure overlaps the temperature of intended use, making the use of test results at a single test temperature extremely dangerous. To improve low temperature properties, prestraining, orienting all the tungsten particles away from the $[100]$ direction, refining the particle size, or alloying are methods which might be used to improve ductility. Alloying appears to be the easiest of these. To improve high temperature strength, again alloying seems the most promising method, but in this case, the alloying addition will have to remain mostly in the matrix, since the matrix controls failure at the elevated temperatures.

\section{REFERENCES}

1. E. G. Zukas, and W. V. Green, "High Density, High Strength Alloys Having Sorne Ductility at Ambient Temperature," Los Alamos Scientific Laboratory Report LA-4670-MS (May 1970).

2. E. I. Larsen, and E. C. Murphy, "Characteristics and Applications of High-Density Tungsten-Bused Composites," The Can. Min. and Met. Bull., pp. 413-421 (1965). 
3. G. H. S. Price, C. J. Smithells, and S. V. Willarns, "Sintered Alloys. Part I. Copper-Nickel-Tungsten Alloys Sintered with a Liquid Phase Present," Jnl. Inst. Met. 62 , pp. 239-264 (1968).

4. C. J. smithells, "Tungsten, Its Metallurgy, Properties ardd Applications," (Chemical Pub. Co., Inc., New York, N.Y., 1953), pp. 258-274.

5. R. H. Krock, "Effect of Composition and Temperature on the Dynamic Elastic Moduli of W-Fe-Ni Composite Materials," Am. Soc. Test. and Mat. $\underline{64}$, pp. $712-718$ (1964).

6. R. H. Krock, "Elastic and Plastic Deformation of Dispersed Phase Liquid Phase Sintered Tungsten Composite Materials, " Metals for the Space Age, F. Benesovsky, Ed., Plansee Proc., Pergamon Press, New York, N.Y., (1965), pp. 256-277.

7. R. H. Krock, 'Some Comparisons Between FiberReinforced and Continuous Skeleton Tungsten-Copper Composite Materials, " Jnl. Mat. 1, pp. 278-291 (1966).

8. R. H. Krock, and L. A. Shepard, "Mechanical Behaviol of the Two-Phase Composite, TungstenNickel-Iron," Tians. AIME 227, pp. 1127-1134 (1963).

9. R. H. Krock, "Solid State Sintering and Particle Growth in Tungsten-Nickel-Iron Composite Material, " Am. Soc. Test. and Mat. 64, pp. 669-680 (1964).

10. R. H. Krock, "Effect of Composition and Dispersed Phase Particle Size Distribution on the Static Elastic Moduli of Tungsten-Copper Composite Materials," Am. Soc. Test. and Mat. 63, pp. 605-612 (1963).

11. R. H. Krock, "The Elastic Modulus of Some Dispersed-Phase Composite Materials," Modern Developments in Powder Metallurgy, Vol. 3, (Plenum Press, 1966), pp. 105-113.

12. R. H. Kroek, "Inorganic Particulate Composites," Modern Compozite Materials, I. J. Broutman and R. H. Krock, Eds. (Addison-Wesley Pub. Co., 1967) pp. $4 \mathbf{5} 5-478$.

13. L. J. Broutman, and R. H. Krock, "Principles of Composites and Composite Reinforcement, "Modern Composite Materials, L. J, Broutman and R. H. Krock, Eds. (Addison-Wesley Pub. Co., 1967), pp. 3-26.

14. R. A. Kurtz, "Properties and Design Considerations of High Density Metals," Tech. Paper \#634 presented at Soc. Aero. Wt. Eng., Boston, Mass. (May 1967).
15. "Kennerium - Machinable Heavy Tungsten Alloy," Pamphlet by Kennametal, Inc., Latrobe, $\mathrm{Pa}$.

16. Richard H. Krock, "Tungsten-Ruthenium Alloy and Powder Metallurgical Method of Making, " U.S. Patent No. 3, 301, 641, January 1967.

17. J. J. Warga, F. D. Evans, and R. J. Kotfila, "Comparison of Pressed and Sintered and Arc-Cast Billets for Refractory Metal Forgings, "Metals for the Space Age, F. Benesovsky, Ed., Plansee Proc., (1964), pp. 184-198.

18. A. Joshi, and D. F. Stein, "Intergranular Brittleness Studies in Tungsten Using Auger Spectroscopy," Met. Trans, 1 , pp. 2543-2546 (1970).

19. B. Paul, "Prediction of Elastic Constants of Multiphase Materials," Trans. AIME 219, pp. 36-42 (1960).

20. Z. Hashin, and S. Shtrikman, "On Some Variational Principles in Elasticity and Their Application to the Theory of Two-Phase Materials, " Armed Services Technical Information Agency Report AD 265-817 (1961),

21. P. E. Armstrong, and H. L. Brown, "Dynamic Young's Modulus Measurements Above $1000^{\circ} \mathrm{C}$ on Some Pure Polycrystalline Metals and Commercial Graphi tes," Trans. AIME 230, pp. 962-966 (1964).

22. J. W. Pugh, "Temperature Dependence of the Tensile Properties of Tantalum," Trans. Am. Soc. Met. $\underline{48}$, pp. $677-688$ (1956).

23. W. J. McGregor Tegart, Elements of Mechanical Metallurgy, (Macmillan, New York (1966).

24. R. P. Carreker, "Tensile Deformation of Silver as a Function of Temperature, Strain Rate, and Grain Size," Trans. AIME 209, pp. 112-120 (1957).

25. R. C. Koo, "Effect of Purity on the Tensile Properties of Tungsten Single Crystals from -196 to $29^{\circ} \mathrm{C}$, " Acta. Met. 11, pp, 1083-1095 (1963).

26. R. G. Garlick, and H. B. Probst, "Investigation of Room Temperature Slip in Zone Melted Tungsten Single Crystals," Trans. AIME $\underline{230}$ pp. 11201125 (1964).

27. D. Hull, and P. Beardmore, "Velocity of Propogation of Cleavage Cracks in Tungsten," Int. Jnl. Fract. Mech. 2, pp. $468-487$ (1966).

28. D. Hull, P. Beardmore, and A. P. Valintine, "Plastic Deformation of Body-Centered-Cubic Metals, " VII-Fracture of Tungsten, Air Force Mat. Lab. Report, AFML-TR-66-369, Vol. II, pp. 1-189 (1967). 
29. P. Beardmore, and D. Hull, "Deformation and Fracture of Tungsten Single Crystals," Jnl. Less Comm. Met. 9, pp. 168-180 (1965).

30. R. M. Rose, D. P. Ferriss, and J. Wulff, "Yielding and Plastic Flow in Single Crystals of Tungsten," Trans. AIME 224, pp. 981-990 (1962).

31. M. Garfinkle, "Room Temperature Tensile Behavior of 100 Oriented Tungsten Single Crystals with Rhenium in Dilute Solid Solutions," Refractory Metals and Alloys IV, R. I. Jaffee, G. M. Ault, J. Maltz, and M. Semchyshen, Eds., (Gordon Breach, New York), Met. Soc. Conf., Vol. 41 (1965), pp. 215-229.
32. J. R. Stephens, and W. R. Witzke, "Alloy Softening in Group VIA Metals Alloyed with Rhenium," Tech. Report NASA-Tn-D-7000, pp. 1-25 (1970).

33. P. L. Raffo, "Yielding and Fracture in Tungsten and Tungsten-Rhenium Alloys," Jnl. Less Comm. Met. 17, pp. 133-149 (1969).

34. J. L. Ratliff, D. J. Maykuth, H. R. Ogden, and R. I. Jaffee, "Tungsten Sheet Alloys with Improved Low Temperature Ductility, "Trans. AIME 230, pp. 490500 (1964).

35. J. W. Pugh, L. H. Amra, and D. T. Hurd, "Properties of Tungsten-Rhenium Lamp Wire," Trans. Am. Soc. Met. 55, pp. 451-461 (1962).

36. B. C. Allen, and R. I. Jaffee, "The Hardness Behavior of Chromium Alloyed with Group IVA to VI Transition Metals," Trans. Am. Soc. Met. $\underline{56}$, pp. 387-402 (1963). 